\title{
Tempos do passado e tempos do futuro em confronto: diferenças e paralelismos
}

\author{
Luís Filipe Cunha
}

Faculdade de Letras da Universidade do Porto / Centro de Linguística da Universidade do Porto ${ }^{1}$

\begin{abstract}
This paper deals with the main similarities and differences that arise between past and future tenses. In particular, we argue that, while the propositions associated with past tenses are completely settled and their truth-value can be evaluated at the speech time, the propositions described by future tenses cannot be seen as true or false at the utterance time since these linguistic forms are ramifying, in that they typically point to a variety of inertia histories or inertia worlds. Nevertheless, if we consider more closely some particular tenses in European Portuguese - namely the Pretérito Imperfeito (Imperfect) and the Pretérito Perfeito do Indicativo (simple past), as representatives of the past tenses, and the Futuro Simples (simple future) and the structure ir ('go') + Infinitive, as representatives of the future ones, we conclude that there are also some important parallels across the two temporal domains. We claim that both the Imperfeito and the Futuro Simples merely locate the situations in a past or future interval, respectively, and that the final interpretation of the sentences in which they occur is the result of the interaction of their temporal characteristics with aspectual and modal features. The Pretérito Perfeito and the structure ir ('go') + Infinitive, on the other hand, share the common property of imposing an additional temporal boundary beyond which the eventualities cannot take place; as a result, aspectual effects and modal readings are much more conditioned and pure temporal interpretations - both in the past and in the future - become greatly predominant.
\end{abstract}

Keywords: semantics, temporal relations, temporal domains, past tenses, future tenses

Palavras-chave: semântica, relações temporais, domínios temporais, tempos do passado, tempos do futuro

\section{Introdução}

Muito embora exista vasta e aprofundada investigação sobre o tema, observamos que, na literatura, está longe de se alcançar um consenso no que se refere a questões como a do estabelecimento da localização temporal das situações ou a da análise a conferir aos diferentes tempos gramaticais em cada língua.

Nesse sentido, emergem visões bastante díspares, mesmo no que à conceção da temporalidade diz respeito. Por exemplo, autores como Reichenbach (1947) adotam uma visão tripartida da linha do tempo - em passado, presente e futuro - e, consequentemente, assumem a prevalência de um certo paralelismo entre tempos do passado e tempos do futuro. Já autores como Declerck $(1991 ; 2006)$ defendem a existência de apenas duas esferas temporais - a do passado e a do não passado (em que se incluem os tempos do futuro) -, o que conduz a uma conceção assimétrica das formas gramaticais envolvidas. ${ }^{2}$

\footnotetext{
${ }^{1}$ Este trabalho teve o apoio do Centro de Linguística da Universidade do Porto, unidade FCT, PEst-OE/LIN/UI0022/2011.

${ }^{2}$ Em favor de uma análise assimétrica para tempos do passado e tempos do futuro, pode evocar-se, por exemplo, a existência em diversas línguas, incluindo o Português, de um tempo que exprime anterioridade em relação a um intervalo passado - o pretérito mais-que-perfeito -, que não encontra correspondência no domínio do porvir, já que se observa a completa ausência de um tempo capaz de exprimir posterioridade em relação a um intervalo futuro.
} 
Não tendo, naturalmente, a pretensão de aprofundar uma temática tão complexa como aquela que acabámos de expor, é nosso objetivo, no entanto, apresentar aqui algumas breves reflexões sobre diferenças e semelhanças que se podem observar entre os tempos do passado e os tempos do futuro, nomeadamente no que diz respeito ao Português Europeu.

Embora se trate, sem dúvida, de uma questão bastante controversa e que se reveste de grande complexidade, procuraremos demonstrar que existem argumentos que apontam tanto para a diferenciação quanto para a aproximação entre certos tempos gramaticais do passado e do futuro.

Nessa medida, tomaremos como nosso objeto de análise o Pretérito Perfeito e o Pretérito Imperfeito do Indicativo (representando os tempos do passado) e o Futuro Sintético e a construção ir (no presente) + Infinitivo (enquanto representantes dos tempos do futuro), no sentido de tentar compreender as divergências que os afastam, mas também de encontrar regularidades que nos permitam reconhecer as propriedades que os aproximam.

Para alcançar os objetivos a que nos propusemos, começaremos, na secção 2 deste trabalho, por fazer uma breve referência a uma questão crucial que tem sido frequentemente invocada para sustentar uma distinção fundamental entre tempos do passado e tempos do futuro, a saber, a atribuição do valor de verdade às proposições descritas. Na secção 3, elencaremos algumas das características básicas dos tempos gramaticais que serão alvo da nossa comparação, nomeadamente o Futuro sintético, a construção ir + Infinitivo, o Pretérito Imperfeito do Indicativo e o Pretérito Perfeito do Indicativo. A secção 4 será dedicada à discussão dos pontos que nos permitem aproximar e distinguir os referidos tempos gramaticais, destacando os paralelismos que se podem surpreender entre tempos do passado e tempos do futuro. Para concluir, apresentaremos algumas considerações finais.

\section{Divergências entre tempos do passado e tempos do futuro: a questão da atribuição do valor de verdade às proposições}

Tal como é comummente reconhecido na literatura (e.g. Besson \& Hattiangadi, 2014; 2020), existe uma divergência fundamental que separa, de forma genérica, os tempos do passado dos tempos do futuro e que se prende com a atribuição do valor de verdade às proposições envolvidas. Enquanto o valor de verdade das proposições associadas aos primeiros se encontra já determinado e pode ser tipicamente aferido no momento da enunciação, os segundos apenas permitem descrever situações potenciais, que poderão eventualmente ter lugar num intervalo posterior ao momento da fala (cf. Prior, 1967).

Como consequência, as proposições asseridas no passado recebem, no momento da enunciação, um valor de verdade único e já perfeitamente estabelecido, ao passo que, no referido intervalo, as proposições localizadas no futuro se encontram ainda em aberto, i.e., o seu valor de verdade não poderá ser especificado na medida em que, no período de tempo relevante, elas ainda não ocorreram.

$\mathrm{Na}$ realidade, o futuro é tipicamente encarado como tendo uma natureza aberta, no sentido em que o seu curso não se encontra previamente determinado, já que são múltiplos os caminhos e as formas que o mundo a que temos acesso no presente pode tomar ao longo do seu desenvolvimento.

Isto significa que, ao contrário do que sucede com os tempos do passado, os tempos do futuro são ramificantes, na medida em que podem ser associados a um conjunto teoricamente infinito de mundos ou de histórias possíveis, o que conduziu diversos autores a explorar conceitos como os de "inertia futures", "inertia histories" ou "inertia worlds" (cf. Prior, 1967; Dowty, 1979; Galton, 2006; Copley, 2009), correspondendo aos diversos "caminhos" possíveis que uma dada situação pode seguir no futuro.

Seguindo a definição proposta em Dowty (1979), mundos ramificantes ou "inertia worlds" "are to be thought of as worlds which are exactly like the given world up to the time in question and in which the future course of events after this time develops in ways most compatible with the past course of events" (Dowty, 1979: 
128). Por outras palavras, tendo em conta o curso dos eventos até ao momento da enunciação, podemos considerar um conjunto de mundos ou de histórias possíveis que se constituem como as "sequências" ou como as "continuações" mais compatíveis com as eventualidades anteriormente ocorridas. Estas serão concebidas como as diferentes histórias possíveis a que o futuro poderá conduzir.

Esta indeterminação quanto ao curso dos eventos num tempo que ainda não ocorreu e ao qual não temos acesso no momento da enunciação conduz ao complexo problema do estabelecimento dos valores de verdade para as proposições localizadas num intervalo do futuro (cf. a discussão em Stojanovic, 2014 ou em Besson \& Hattiangadi, 2014; 2020).

Uma hipótese para dar conta desta indefinição que caracteriza os tempos do futuro seria a de assumir que, pelo menos no momento da enunciação, não é exequível atribuir qualquer valor de verdade às proposições que descrevem situações localizadas num intervalo que lhe é posterior: dado que não nos encontramos em condições de saber qual o rumo que os acontecimentos no futuro vão tomar, i.e., qual o mundo possível que irá corresponder ao curso real dos eventos, o valor de verdade para estas frases não está acessível no momento da enunciação e as proposições em questão limitar-se-iam a dar conta de meras possibilidades, hipóteses ou probabilidades. Este raciocínio está na base das análises que concebem os futuros enquanto expressão da modalidade epistémica (cf., por exemplo, Giannakidou, 2014; Giannakidou \& Mari, 2018).

No entanto, são muitos os casos em que o recurso aos tempos do futuro não se limita a apontar simples alternativas mais ou menos prováveis. Por exemplo, numa previsão meteorológica, quando se diz que "vai chover amanhã no Porto", não se está meramente a colocar uma hipótese, entre muitas outras, igualmente plausíveis, de que existe uma possibilidade de que vá chover no dia seguinte na referida cidade. Pelo contrário, está-se a fazer uma previsão ou a assumir-se que, num determinado intervalo do futuro, i.e., amanhã, e dado o conhecimento atual do mundo, a situação de "chover no Porto" vai efetivamente ter lugar. Isto significa que é realmente possível produzir asserções sobre intervalos posteriores ao momento da enunciação e atribuir-lhes um dado valor de verdade, mesmo mantendo a ideia de que o futuro é, sob um certo ponto de vista, "aberto", tal como argumentam, por exemplo, Belnap e Green (1994), MacFarlane (2003; 2008) ou Besson e Hattiangadi $(2014 ; 2020)$.

Trata-se, por conseguinte, de tentar compatibilizar duas conceções aparentemente contraditórias do futuro: se, por um lado, este deve ser encarado como não determinista, no sentido em que existem vários rumos ou histórias possíveis para a sua concretização, deve, por outro, estar associado a algum tipo de determinismo, na medida em que é intuitivamente possível atribuir um valor de verdade (verdadeiro ou falso) às proposições descritas.

Com o objetivo de solucionar o problema em apreço, MacFarlane (2003) sugere que a avaliação do valor de verdade das proposições no futuro deve ser relativizada a um dado contexto: quando encarada a partir do momento da enunciação $(m 0)$, uma proposição no futuro não poderia receber um valor de verdade especificado, o que é compatível com a visão indeterminista do futuro; se, porém, tomarmos um momento $m 1$ posterior a $m 0$ em que a situação relevante possa ser acedida, então torna-se possível atribuir um valor de verdade (positivo ou negativo) à proposição em causa, o que estaria de acordo com a visão determinista do futuro.

Por outras palavras, a atribuição de um valor de verdade a uma proposição no futuro é relativa a um dado contexto de avaliação e deve ser feita não apenas em relação ao momento da enunciação (o seu contexto de produção), mas também em relação ao intervalo de tempo posterior em que a situação é localizada (o seu contexto de realização; cf. MacFarlane, 2003; 2008).

Uma outra alternativa, ainda mais radical, passaria por considerar que, ao asserirmos uma proposição no futuro, estamos a privilegiar apenas uma (e só uma) de entre as diferentes histórias possíveis que o curso dos acontecimentos pode tomar. Essa história corresponderia ao fluxo dos eventos no mundo real. Todas as outras histórias possíveis, embora relevantes em termos epistémicos, não seriam consideradas na altura da atribuição de um valor de verdade à proposição em causa. Nesta perspetiva, o valor de verdade atribuído a uma dada 
proposição terá apenas em conta a verdade ou a falsidade da situação descrita no mundo de referência, independentemente de todas as restantes histórias alternativas que eventualmente possam vir a ser consideradas. Tal como nas propostas de MacFarlane, essa história "privilegiada" decorre num intervalo que inclui o momento da enunciação e se prolonga no futuro; embora, naturalmente, o seu valor de verdade não possa ser acedido no momento da fala, tal intervalo está indissociavelmente ligado ao todo da história considerada. Propostas neste sentido são designadas, na literatura, como o futuro enquanto "Thin red Line" (vejam-se, entre outros, Belnap \& Green, 1994 ou Malpass \& Wawer, 2012).

Seja como for, e independentemente do caminho que se queira adotar, é importante sublinhar que, mesmo que subsista um alto grau de indeterminação no momento da enunciação, continua a ser perfeitamente possível produzir asserções acerca de estados de coisas futuros e, dados os contextos adequados, atribuir-lhes um valor de verdade.

Isto não significa, no entanto, que tempos do passado e tempos do futuro não sejam radicalmente diferentes a este nível. Com efeito, enquanto as proposições associadas aos primeiros têm o seu valor de verdade perfeitamente estabelecido no momento da enunciação, isso não se verifica em relação aos segundos.

Apesar desta divergência substancial, parecem existir também pontos de contacto significativos entre certos tempos do passado e do futuro que abrem caminho a uma análise mais sistemática de algumas das suas propriedades semânticas fundamentais. Antes, porém, de explorarmos essas similitudes, importa ressaltar, ainda que de forma bastante resumida, um conjunto de características básicas que nos permitem identificar os tempos gramaticais que serão alvo da nossa comparação.

\section{Algumas observações sobre tempos gramaticais}

Para a nossa discussão das semelhanças que se podem observar entre tempos do passado e tempos do futuro selecionámos quatro formas do Português Europeu: o Pretérito Perfeito e o Pretérito Imperfeito do Indicativo, enquanto representantes dos tempos do passado, e o Futuro Simples e a construção ir (no presente) + Infinitivo, ilustrando os tempos do futuro. Como veremos, o Futuro Simples e o Pretérito Imperfeito, por um lado, e a construção ir + Infinitivo e o Pretérito Perfeito, por outro, partilham comportamentos linguísticos reveladores a que importa prestar atenção. Antes disso, porém, vejamos algumas das propriedades semânticas que caracterizam os tempos gramaticais em questão.

\subsection{Considerações prévias sobre o Futuro Simples e a construção ir + Infinitivo}

No sentido de facilitar uma comparação sistemática entre os tempos gramaticais que aqui selecionámos, assumiremos, neste trabalho, uma perspetiva de análise para as formas de futuro que toma como ponto de partida as relações temporais por elas estabelecidas. Assim, adotaremos aqui o enquadramento teórico proposto por Gennari (2000; 2002), que, com base em dados do espanhol, mas que em muito se assemelham aos do Português, defende um tratamento unificado para o Futuro Simples do Indicativo e sustenta que esta forma verbal veicula consistentemente informação temporal de posterioridade em relação ao momento da enunciação.

Gennari $(2000$; 2002) propõe, para o Futuro Sintético do espanhol, um tratamento que envolve a consideração simultânea e integrada de fatores temporais, modais e aspetuais. O Futuro Sintético é encarado como um tempo gramatical que localiza de forma sistemática as situações com que coocorre num intervalo posterior ao momento da enunciação, podendo, igualmente, em certos contextos específicos, interagir com a valor aspetual das situações com que se combina e comportar informação de natureza modal.

Uma análise como esta permite dar conta de alguns dos comportamentos mais relevantes manifestados pelo Futuro Simples também no Português Europeu, tal como procuraremos demonstrar em seguida.

Primeiramente, importa sublinhar que a proposta teórica em questão é perfeitamente compatível com o facto de existirem contextos em que o Futuro Simples se limita a localizar as situações com que se combina 
num intervalo de tempo posterior ao momento da enunciação, sem manifestar marcas explícitas de modalidade. Referimo-nos, nomeadamente, (i) às frases que expressam de forma inequívoca a certeza quanto à realização futura das eventualidades envolvidas (cf. (1)); (ii) aos contextos em que o nosso conhecimento do mundo ou do funcionamento de determinados fenómenos naturais nos leva a assumir a necessidade ou a inevitabilidade da ocorrência de um acontecimento previsível (cf. (2)) ou (iii) a construções envolvendo certos adverbiais de localização precisa ou exata num período de tempo prospetivo que, ao fixarem um intervalo bem definido para a realização das eventualidades em causa, contribuem decisivamente para a consideração da sua efetiva concretização (cf. (3)).

(1) O coleccionismo encontrará sem dúvida estímulos suficientes nos 1200 criadores das últimas tendências artísticas que se expõem na Feira. (CetemPúblico, par=ext1186992-nd-92a-1) ${ }^{3}$

(2) Mas, quando as chuvas pararem, daqui a umas semanas, e a comida começar a escassear, o destino destes insectos já está marcado: formarão imensas nuvens vivas e migrarão para as regiões habitadas e cultivadas. (CetemPúblico, par=ext1077164-clt-soc-93b-2)

(3) Na sexta-feira, dia 5, a sessão abrirá às 21h, com «Projecto Tojeira», de Madalena Vitorino, num vídeo de Paulo Abreu, seguindo-se «Interiors» e «Teaser», de Rui Horta, por Bruno Perosa; «Carceri d'Invenzione», de Ana Moura, por Edgar Feldman; «Saudade», de Luís Damas, por Miranda Ferreira e Pedro Humberto; «Três Solos», de Olga Roriz, por Rui Simões; (...) (CetemPúblico, par=ext1 1859clt-93a-2 $)^{4}$

Isto não significa, no entanto, que ao valor temporal básico do Futuro Simples não se possam adicionar outras interpretações relevantes. Nessa medida, é perfeitamente possível surpreender a coexistência, numa mesma frase, de uma componente inequivocamente temporal (projeção para o futuro) e de informação de cariz claramente modal, por exemplo de modalidade epistémica, tal como ilustrado em (4):

(4) São 19 horas em Newcastle (Inglaterra) e o navio vai zarpar dentro de poucos minutos, rumo a Bergen, na Noruega, onde só chegará (= deve chegar) na tarde do dia seguinte. (CetemPúblico, par=ext17258soc-95b-1)

Por outro lado, e como já referimos anteriormente, a proposta de Gennari $(2000 ; 2002)$ toma igualmente em linha de conta as restrições aspetuais que afetam a interpretação do Futuro Simples e que condicionam sobretudo as designadas leituras hipotéticas ou conjeturais a que este tempo gramatical se encontra frequentemente associado.

Nos usos conjeturais ou de incerteza, tal como observado por autores como Martin (1981), Dendale (2001) ou Laca (2016), o Futuro Simples não projeta a situação com que comparece num intervalo posterior ao "agora" enunciativo; pelo contrário, apresenta-a como uma hipótese ou como uma possibilidade a ser avaliada

\footnotetext{
${ }^{3}$ Ao longo do presente trabalho recorreremos, sempre que possível, a exemplos reais, retirados do corpus CetemPúblico, disponível em www.linguateca.pt. No entanto, e dado que grande parte da nossa discussão passa pela manipulação de frases, no sentido de tornar a comparação entre as estruturas relevantes livre de qualquer tipo de interferências por parte de outros elementos linguísticos, também surgirão frequentemente exemplos criados por nós.

${ }^{4}$ Note-se que, em exemplos como estes, o Futuro Simples é preferencialmente parafraseável pela forma $i r$ + Infinitivo, não podendo ser substituído por verbos modais como poder ou dever sem que o significado global das frases se altere substancialmente.
} 
(confirmada ou infirmada) num intervalo que tipicamente inclui o momento da enunciação, como o exemplo (5) parece corroborar.

(5) O «pequeno timoneiro», 91 anos em Agosto, se lá chegar, já não é visto em público desde Fevereiro de 1994 e estará gravemente doente. (CetemPúblico, par=ext1179544-pol-95a-2)

A uma primeira vista, frases como estas poderiam ser invocadas como contraexemplos em relação à proposta de análise defendida por Gennari (2000; 2002), uma vez que, aparentemente, não se verifica, neste género de contextos, a localização futura das situações envolvidas.

Existem, no entanto, razões que nos levam a acreditar que esta questão se reveste de contornos bastante mais complexos. Em primeiro lugar, importa sublinhar que a interpretação puramente conjetural do Futuro Simples se restringe a predicações de cariz estativo, encontrando-se os eventos impedidos de a receber, como o contraste entre os exemplos que se seguem nos comprova:

(6) O João estará agora na faculdade. (estado)

(7) A Maria viverá agora em Paris. (estado)

(8) \# O João conversará agora com os colegas. (processo)

(9) \# A Rita lerá agora o seu livro preferido. (processo culminado)

(10) \# O Luís ligará agora o computador. ${ }^{5}$ (culminação)

A provar que o fator determinante para o licenciamento destas leituras hipotéticas é a natureza aspetual das predicações envolvidas pode ser invocado o facto de que, quando aplicamos um operador aspetual com função estativizadora às construções eventivas relevantes, como é o caso da forma do Progressivo (cf. Cunha, 1998), as frases tornam-se perfeitamente aceitáveis na interpretação requerida (cf. (11)-(13)):

(11) O João estará agora a conversar com os colegas.

(12) A Rita estará agora a ler o seu livro preferido.

(13) O Luís estará agora a ligar o computador.

Ora, a análise sugerida por Gennari mostra-se perfeitamente capaz de lidar com estes factos, na medida em que (i) ao postular uma relação consistente de posterioridade do intervalo em que decorre a situação descrita face ao momento da enunciação, permite explicar a inadequação de exemplos como os de (8)-(10), em que tal relação não se verifica; e (ii) em conjugação com as propostas de Kamp e Rohrer (1983) e de Kamp e Reyle (1993), que assumem que os estados, ao contrário dos eventos, se podem prolongar para além das fronteiras dos respetivos intervalos de realização, permite acomodar a aceitabilidade de exemplos como (6)-(7) (e também (11)-(13)), na medida em que a leitura de sobreposição ao momento da enunciação não resultaria das propriedades temporais do Futuro Simples, mas antes das características aspetuais das predicações envolvidas, em particular a possibilidade manifestada pelos estados para se prolongarem para além do seu intervalo de realização.

\footnotetext{
${ }^{5}$ Para a nossa discussão, apenas são relevantes as leituras em que se verifica sobreposição ao momento da enunciação; os eventos representados podem, naturalmente, ser interpretados com um valor prospetivo, mas, nesse caso, não apresentam qualquer dificuldade para a proposta de análise que aqui estamos a debater.
} 
As interpretações conjeturais atribuídas ao Futuro Simples, assim como as restrições que lhes estão associadas, surgiriam, pois, como o resultado esperado da interação entre fatores temporais e aspetuais, não sendo posta em causa a sua propriedade básica de localizar as eventualidades num intervalo posterior ao momento da enunciação. ${ }^{6}$

Para além de notórias divergências ao nível discursivo e pragmático, que não serão consideradas neste trabalho, a construção ir (no Presente do Indicativo) + Infinitivo partilha com o Futuro Simples a propriedade de localizar as situações com que se combina num intervalo de tempo posterior ao momento da enunciação. Isto não significa, contudo, que não existam diferenças semânticas significativas entre as duas formas consideradas.

Assim, observamos que a construção ir + Infinitivo parece não poder ocorrer em configurações hipotéticas ou conjeturais em que se verifique a sobreposição da eventualidade descrita ao momento da enunciação, mesmo quando estão envolvidas predicações de natureza estativa, como os exemplos seguintes nos revelam:

(14) \# O João vai estar agora na faculdade. (estado)

(15) \# A Maria vai viver agora em Paris. (estado)

As frases em (14)-(15) contrastam com as suas equivalentes em (6)-(7), na medida em que, para serem interpretáveis, obrigam ao estabelecimento de uma relação de posterioridade das situações envolvidas em relação ao ponto de fala, não desencadeando a leitura conjetural ou hipotética de sobreposição que caracteriza o Futuro Simples em contextos semelhantes.

Por outro lado, e como veremos com mais pormenor na secção 4 do presente trabalho, a construção $i r+$ Infinitivo está sujeita a fortes restrições no que respeita à expressão de valores modais, o que não sucede com o Futuro Simples.

Em suma, embora ambas as formas remetam para a localização ulterior das eventualidades com que coocorrem, Futuro Simples e ir + Infinitivo não podem ser concebidas como estruturas semanticamente idênticas, facto que iremos explorar mais adiante, quando estabelecermos uma comparação sistemática entre tempos do passado e tempos do futuro.

\subsection{Alguns dados para uma caracterização preliminar do Pretérito Perfeito e do Pretérito Imperfeito do Indicativo}

Em termos gerais, diremos que o Pretérito Imperfeito do Indicativo pode ser caracterizado como um tempo do passado que apresenta uma dada eventualidade como estando em progressão, i.e., sem fazer qualquer referência aos seus momentos inicial e final (cf. Oliveira, 1987; 2013; Delfitto \& Bertinetto, 1995; Smith, 1991; Giorgi \& Pianesi, 1997, entre outros).

Relativamente ao seu comportamento semântico, assumiremos os seguintes postulados:

(i) Trata-se de um tempo relativo ou anafórico, na medida em que requer a presença de um intervalo no passado que lhe sirva como ponto de ancoragem (cf. Declerck, 1991; 2006; Oliveira \& Lopes, 1995; Matos, 1996). Esse intervalo pode ser fornecido por um adverbial temporal explícito, por

\footnotetext{
${ }^{6}$ Existem, obviamente, muitas outras propostas alternativas para a caracterização semântica do Futuro Simples, nomeadamente teorias que defendem a ambiguidade da referida forma entre um tempo gramatical e um operador modal (Mari, 2009; Giomi, 2010; Falaus \& Laca, 2014; Laca, 2016; Marques, 2020). Dado o propósito do presente trabalho, porém, optámos pela adoção da análise de Gennari, não nos sendo possível, por questões de espaço, aprofundar o debate entre as várias abordagens apresentadas para o estudo da construção em apreço. Para uma discussão comparativa de diferentes propostas de tratamento do Futuro Simples em Português, veja-se, por exemplo, Cunha (2019; 2021).
} 
orações temporais, pelo verbo principal de uma estrutura de complementação ou recuperado através de indicações contextuais.

(ii) Sob esse ponto de vista, diversos autores consideram o Pretérito Imperfeito como constituindo a expressão de um "presente do passado" (cf. e.g. Cunha \& Cintra, 1984), ou, mais rigorosamente, como descrevendo uma relação de sobreposição a um intervalo passado (cf. Peres, 1993; Giorgi \& Pianesi, 1997).

(iii) Em línguas como o Português, o Pretérito Imperfeito funciona como um verdadeiro estativizador, na medida em que, tal como os estados lexicais, parece não introduzir um novo Tempo de Referência no discurso, limitando-se a selecionar um dado intervalo preexistente com o qual estabelece uma relação de sobreposição (cf. Kamp \& Rohrer, 1983) e, quando combinado com eventos, altera significativamente o seu perfil aspetual básico, impondo-lhes propriedades semânticas típicas das predicações estativas, seja conferindo-lhes uma interpretação de cariz habitual, como em (16), seja impondo-lhes uma leitura semiprogressiva, como em (17) (cf. Oliveira \& Lopes, 1995; Cunha, 2004/2007; Oliveira, 2013).

(16) Monty viveu no Hotel Roosevelt enquanto filmou e passeava todas as noites nos corredores do nono andar lendo os seus diálogos em voz alta. (CetemPúblico, par=ext28053-clt-94a-1) (leitura habitual)

(17) Quando passeava (= estava a passear) junto ao mar, uma jovem escorregou e caiu à água, tendo o seu pai tentado salvá-la: ao fim da tarde de ontem, só o corpo da jovem de 18 anos tinha sido recuperado. (CetemPúblico, par=ext9533-nd-96b-2) (leitura semiprogressiva)

Dada a caracterização que acabámos de fornecer, podemos concluir que o Pretérito Imperfeito introduz um estado que se sobrepõe a um determinado intervalo que, por sua vez, estabelece uma relação de anterioridade com o momento da enunciação.

Em termos gerais, diremos que o Pretérito Perfeito do Indicativo pode ser caracterizado como um tempo do passado que localiza uma dada eventualidade terminada num intervalo anterior ao momento da enunciação (cf. Cunha, 2004/2007; Oliveira, 2013).

Relativamente à sua caracterização semântica, assumiremos os seguintes postulados:

(i) Trata-se de um tempo gramatical que localiza as situações com que se combina num intervalo de tempo anterior ao momento da enunciação.

(ii) O Pretérito Perfeito não altera substancialmente o perfil aspetual das eventualidades com que se combina, pelo que pode ser considerado um elemento aspetualmente neutro. A comprovar esta afirmação podemos invocar o facto de que as propriedades temporais internas básicas das predicações são preservadas em estruturas que integram este tempo gramatical, como os diferentes padrões de combinação com os adverbiais temporais relevantes apresentados em (18)(21) parecem confirmar: ${ }^{7}$

(18) A Maria esteve doente durante uma semana. (estado)

(19) A Joana passeou no jardim durante duas horas. (processo)

\footnotetext{
${ }^{7}$ Recorremos aqui aos testes clássicos que, na literatura, são utilizados para a identificação das diferentes classes aspetuais de predicações. Para uma discussão pormenorizada acerca do seu funcionamento, vejam-se, e.g., Vendler (1967), Moens (1987) ou Smith (1991).
} 
(20) O Pedro podou a laranjeira em meia hora. (processo culminado)

(21) O Rui partiu o vaso às cinco da tarde. (culminação)

(iii) O Pretérito Perfeito pode ser considerado um tempo "terminativo", no sentido em que requer que as situações com que coocorre se encontrem confinadas a um intervalo obrigatoriamente anterior ao momento da enunciação (cf. Cipria \& Roberts, 2000; Cunha, 2004/2007; Oliveira, 2013). No entanto, é importante sublinhar que a terminatividade impõe apenas um limite final às eventualidades em causa, não interferindo com a sua estrutura interna. Ou seja, o facto de as situações serem concebidas como estando terminadas não significa, de nenhum modo, que se encontrem concluídas ou completas, no sentido aspetual do termo. A confirmar esta afirmação podemos invocar a plena compatibilidade do Pretérito Perfeito com formas do progressivo: se "ontem, o João esteve a escrever o relatório" implica que a situação terminou antes do momento da enunciação, tal não quer dizer que tenha alcançado a sua culminação, i.e., não acarreta que "o relatório foi / está escrito".

Dada a caracterização que acabámos de fornecer, podemos concluir que o Pretérito Perfeito se limita a localizar uma dada situação num intervalo anterior ao momento da enunciação, requerendo apenas que esta se encontre terminada antes de $t 0$.

A presente secção não teve, naturalmente, a intenção de oferecer uma descrição semântica completa e aprofundada dos diferentes tempos verbais selecionados. Pretendeu apenas lançar algumas pistas que nos serão de grande utilidade para a comparação a que procederemos seguidamente.

\section{Alguns pontos de contacto entre tempos do passado e tempos do futuro}

A hipótese que desenvolveremos ao longo da presente secção será a de que certos tempos do passado e certos tempos do futuro, embora atuando em domínios temporais perfeitamente distintos, partilham importantes propriedades semânticas que lhes são comuns.

$\mathrm{Na}$ realidade, apesar das divergências a que já fizemos referência, existem, igualmente, características relevantes que aproximam claramente certos tempos do passado e do futuro. Em particular, veremos que o Pretérito Imperfeito e o Futuro Simples, por um lado, e o Pretérito Perfeito e a construção ir + Infinitivo, por outro, compartilham alguns comportamentos linguísticos, cujo estudo pode contribuir para uma melhor compreensão da organização e do funcionamento do sistema de tempos gramaticais do Português. Veremos, em seguida, aqueles que se nos afiguram mais significativos. ${ }^{8}$

\subsection{A relação com o momento da enunciação}

Como já referimos brevemente em 3.1, uma das características mais evidentes que permitem diferenciar o Futuro Simples da construção ir + Infinitivo prende-se com a (im)possibilidade de estabelecer uma relação de sobreposição das situações descritas com o momento da enunciação.

A comprová-lo podemos invocar o facto de o Futuro Simples poder, quando estão envolvidas predicações de natureza estativa e reunidas todas as circunstâncias adequadas, dar origem a leituras em que se obtém uma

\footnotetext{
${ }^{8}$ Embora, na literatura, seja frequentemente referida a proximidade entre tempos do passado e tempos do futuro, não é do nosso conhecimento qualquer abordagem que estabeleça uma comparação sistemática entre os tempos que aqui estamos a analisar, sendo esta nossa hipótese perfeitamente original nesse sentido.
} 
relação de sobreposição da eventualidade descrita com o momento da enunciação (cf. (22)-(23)). Trata-se dos designados usos conjeturais ou hipotéticos do futuro a que já aludimos anteriormente: ${ }^{9}$

(22) Os traficantes de droga estarão (agora) na Colômbia.

(23) Assim, a maior parte dos trabalhadores despedidos nessa altura viverá agora com «mais problemas», e a doença, a insegurança e a solidão são as situações mais evidenciadas. (CetemPúblico, par=ext399485-nd-91b-2)

Uma tal possibilidade parece estar completamente vedada à construção $i r$ + Infinitivo, que, nos contextos em causa, apenas admite leituras de posterioridade, como (24) e (25) deixam transparecer.

(24) \# Os traficantes de droga vão estar (* agora) na Colômbia.

(25) \# Assim, a maior parte dos trabalhadores despedidos nessa altura vai viver agora com «mais problemas», e a doença, a insegurança e a solidão são as situações mais evidenciadas.

A serem aceites, as únicas interpretações possíveis para as frases em (24) e (25) são aquelas em que as situações descritas ocorrem num intervalo de tempo necessariamente posterior ao momento da fala, sendo excluída qualquer leitura que aponte para a sobreposição.

Parece dar-se um contraste semelhante quando observamos o comportamento dos tempos do passado que aqui estamos a investigar.

Assim, observamos que o Pretérito Imperfeito, na medida em que tipicamente funciona como um estativizador (cf. Oliveira \& Lopes, 1995; Cunha, 2004/2007; Oliveira, 2013), permite, em condições adequadas, que as eventualidades que com ele comparecem se prolonguem até ao momento da enunciação, com o qual podem eventualmente estabelecer uma relação de sobreposição, pelo menos parcial (cf. (26)-(27)):

(26) A Ana estava na faculdade e provavelmente ainda lá está.

(27) O Pedro tinha um cão enorme; ainda o deve levar a passear ao jardim todos os dias.

O Pretérito Perfeito, pelo contrário, nunca admite este tipo de interpretação: as situações com que se combina são obrigatoriamente localizadas num intervalo anterior ao ponto de fala, não podendo prolongar-se até ao momento da enunciação, independentemente de estarem em causa estados ou eventos. Não surpreende, por conseguinte, que as frases em (28) e (29), paralelas a (26) e (27), mas em que o Pretérito Imperfeito foi substituído pelo Pretérito Perfeito, se revelem inaceitáveis:

(28) A Ana esteve na faculdade * e provavelmente ainda lá está.

(29) O Pedro teve um cão enorme; * ainda o deve levar a passear no jardim todos os dias.

Os dados que acabámos de apresentar abrem caminho às seguintes generalizações:

\footnotetext{
${ }^{9}$ Para uma descrição mais detalhada deste tipo de estruturas, vejam-se, entre muitos outros, Martin (1981) ou Dendale (2001).
} 
Na medida em que permitem, em circunstâncias adequadas, que as situações com que coocorrem estabeleçam uma relação de sobreposição (ainda que parcial) com o momento da enunciação, tanto o Pretérito Imperfeito, em relação ao passado, quanto o Futuro Simples, em relação ao futuro, revelam-se temporalmente menos restritivos do que o Pretérito Perfeito e do que a estrutura ir + Infinitivo, que localizam forçosamente as eventualidades com que comparecem, na íntegra, em intervalos situados antes ou depois do ponto de fala, respetivamente.

(ii) O Pretérito Imperfeito e o Futuro Simples distinguem-se, igualmente, do Pretérito Perfeito e da estrutura $i r$ + Infinitivo pelo facto de se mostrarem sensíveis às diferenças aspetuais das situações com que comparecem; em particular, admitem leituras de sobreposição ao momento da enunciação somente quando estão em causa predicações de natureza estativa (básica ou derivada). Pelo contrário, tanto o Pretérito Perfeito quanto a construção ir + Infinitivo se revelam "neutros" em relação às classes aspetuais das eventualidades descritas, visto que as situam consistentemente num intervalo inteiramente localizado no passado ou no futuro, independentemente das propriedades inerentes ao seu perfil temporal interno.

\subsection{A expressão de valores modais}

Uma outra característica que claramente separa o Futuro Simples da estrutura $i r+$ Infinitivo prende-se com a facilidade com que a primeira destas formas integra configurações que expressam valores de natureza modal (cf. Oliveira, 1986; Giannakidou \& Mari, 2018; Marques, 2020).

Assim, e para além dos casos, anteriormente mencionados, em que nos deparamos com o designado futuro hipotético ou conjetural, encontramos com facilidade exemplos em que o Futuro Simples pode veicular modalidade epistémica (cf. (30)) ou, embora com menor frequência, modalidade deôntica (cf. (31)):

(30) Em contrapartida, enquanto há cinco meses os técnicos da Comunidade não acreditavam que a inflação portuguesa descesse abaixo dos 12,5 por cento, consideram agora que ela chegará (= pode / deve chegar) ao final do ano em apenas 11,5 por cento. (CetemPúblico, par=ext32253-eco-91a-1)

(31) O mandamento da avó de Russell não podia ser mais claro: não seguirás uma multidão para fazer o mal. (CetemPúblico, par=ext769053-nd-93b-2)

Embora a estrutura ir + Infinitivo também possa, em determinadas circunstâncias, ostentar valores modais, na generalidade dos casos limita-se a veicular informação de cariz temporal. Este facto torna-se bem evidente se comutarmos as formas de Futuro Simples, nos exemplos acima, pela referida construção:

(32) Em contrapartida, enquanto há cinco meses os técnicos da Comunidade não acreditavam que a inflação portuguesa descesse abaixo dos 12,5 por cento, consideram agora que ela vai chegar ao final do ano em apenas 11,5 por cento.

(33) O mandamento da avó de Russell não podia ser mais claro: não vais seguir uma multidão para fazer o mal.

O significado modal de (30)-(31) é fortemente atenuado (senão mesmo perdido) em exemplos como (32)(33), em que a interpretação puramente temporal se mostra claramente predominante. Assim, enquanto em (30) a chegada do valor da inflação aos 11,5 por cento nos é apresentada como uma mera possibilidade, em (32) ela surge quase como uma certeza. De um modo semelhante, enquanto o mandamento de não seguir uma multidão para fazer o mal é interpretado em (31) como uma obrigação ou como uma norma a cumprir, esse valor parece 
sofrer um certo enfraquecimento em (31), em que $i r+$ Infinitivo remete sobretudo para uma previsão acerca do que se irá passar no futuro. ${ }^{10}$

Paralelamente, no domínio do passado, o Pretérito Imperfeito surge como um tempo gramatical particularmente apto para integrar construções em que a expressão da modalidade é preponderante, como tem sido profusamente observado na literatura (e.g. Oliveira, 1987; 2013; Cipria \& Roberts, 2000; Ippolito, 2004; Anand \& Acquard, 2009).

Exemplos de usos modais do Pretérito Imperfeito são, entre outros, o designado imperfeito onírico ou ficcional, em que é descrito o conteúdo de sonhos, de cenas ficcionadas ou de acontecimentos imaginários (cf. (34)); o imperfeito de cortesia, utilizado para atenuar a força ilocutória de ordens ou de pedidos (cf. (35)); o imperfeito de planificação, que projeta para um intervalo no futuro algo que está a ser planeado pelo locutor no momento da enunciação (cf. (36)); o imperfeito hipotético ou de probabilidade, que descreve situações hipotéticas ou possibilidades a considerar (cf. (37)-(38)) e que ocorre por vezes no contexto de orações condicionais:

(34) Nessa noite, Simão Kimbangu, catequista, antigo aluno de uma missão baptista inglesa, sonhou que um anjo o visitava. (CetemPúblico, par=ext4564-nd-95a-1)

(35) Queria um café e um bolo, por favor.

(36) Então, amanhã, eu encontrava-me contigo na faculdade.

(37) "Se tivesse esse dinheiro, comprava um jogador hoje." (CetemPúblico, par=ext734550-des-95b-1)

(38) "Tinha duas opções: ou comprava um grande barco e passava o resto da vida deitado ao sol, ou então dedicava-me a ajudar as pessoas do meu país". (CetemPúblico, par=ext359416-pol-94b-2)

A expressão de uma tal diversidade de valores modais está completamente vedada ao Pretérito Perfeito, como os exemplos seguintes, em que este tempo gramatical substitui as formas relevantes de Pretérito Imperfeito presentes em (34)-(38), deixam bem claro:

(39) Nessa noite, Simão Kimbangu, catequista, antigo aluno de uma missão baptista inglesa, sonhou que um anjo o visitou.

(40) * Quis um café e um bolo, por favor.

(41) * Então, amanhã, eu encontrei-me contigo na faculdade.

(42) * "Se tivesse esse dinheiro, comprei um jogador hoje".

(43) * "Tinha/tive duas opções: ou comprei um grande barco e passei o resto da vida deitado ao sol, ou então dediquei-me a ajudar as pessoas do meu país".

À exceção do que acontece com o designado imperfeito onírico ou ficcional, que parece alternar sem problemas com o Pretérito Perfeito (embora, para a maioria dos falantes, os significados das duas variantes possam divergir sensivelmente; cf. o contraste entre (34) e (39)), observamos que os usos modais que atribuímos

\footnotetext{
${ }^{10}$ Não queremos com isto afirmar, naturalmente, que a construção ir + Infinitivo não possa ocorrer em contextos claramente modais, como é o caso de certas orações condicionais do género de (i). O que pretendemos sublinhar é apenas que tais interpretações são claramente desfavorecidas com este tipo de estrutura em comparação com o Futuro Simples.
}

(i) Se eu ganhar o euromilhões, vou comprar uma mansão enorme. 
ao Pretérito Imperfeito não estão disponíveis para as formas equivalentes do Pretérito Perfeito, que dão origem a estruturas agramaticais nos contextos relevantes.

Com base na discussão que levámos a cabo até aqui, podemos formular a seguinte generalização, que correlaciona fatores temporais e modais:

Os tempos gramaticais que se mostram menos restritivos em termos de localização das predicações com que se combinam, i.e., que admitem, para além da sua leitura básica, a possibilidade de sobreposição ao momento da enunciação, nomeadamente o Pretérito Imperfeito, em relação ao passado, e o Futuro Simples, em relação ao futuro, revelam-se particularmente aptos para receber interpretações de natureza modal.

(ii) Já os tempos gramaticais que manifestam maiores restrições quanto à localização das predicações com que coocorrem, i.e., que impõem leituras unicamente de passado ou de futuro às situações que perspetivam, nomeadamente o Pretérito Perfeito e a construção $i r$ + Infinitivo, não parecem particularmente adequados para a expressão da modalidade, o que não significa, no entanto, que, em circunstâncias muito específicas, não possam receber também esse tipo de interpretações.

\subsection{Descrição de valores temporais}

Regressando à análise das propriedades temporais das formas que têm sido alvo da nossa atenção, podemos afirmar que, mais uma vez, faz sentido agrupar o Pretérito Imperfeito e o Futuro Simples, por um lado, e o Pretérito Perfeito e a construção $i r+$ Infinitivo, por outro.

$\mathrm{Na}$ realidade, tanto o Pretérito Imperfeito quanto o Futuro Simples parecem limitar-se a localizar as situações com que se combinam num intervalo do domínio do passado ou do domínio do futuro, respetivamente, sem imporem qualquer tipo de constrangimento adicional em termos de temporalidade. Este facto permitirá explicar, por exemplo, a sensibilidade ao perfil aspetual das eventualidades envolvidas, em particular no que respeita à possibilidade de os estativos se poderem prolongar para além do seu tempo de realização, sobrepondose, assim, total ou parcialmente, ao momento da enunciação, tal como previsto por propostas como as de Kamp e Rohrer (1983) ou de Kamp e Reyle (1993).

O Pretérito Perfeito e a construção ir + Infinitivo, por seu lado, para além de promoverem a localização em intervalos do passado ou do futuro, respetivamente, parecem requerer uma restrição adicional, a saber, a imposição de uma fronteira temporal para além da qual as eventualidades com que coocorrem não se poderão estender. Essa restrição impede, pois, o prolongamento das situações em questão até ao momento da enunciação, mesmo que se encontrem reunidas as condições aspetuais que o permitam.

No caso do Pretérito Perfeito, advogamos, na esteira de Cunha (2004/2007), a presença de uma fronteira final no passado, para além da qual as eventualidades não poderão continuar. Assim se explicaria a ideia de terminatividade que é muitas vezes atribuída na literatura a esse tempo gramatical.

No que respeita à estrutura $i r$ + Infinitivo, para a qual não encontrámos, na literatura consultada, qualquer caracterização pormenorizada, advogamos aqui a introdução, na sua constituição temporal, de uma fronteira inicial, localizada no futuro, para além da qual a situação não poderá decorrer, constituindo, por assim dizer, uma espécie de imagem em espelho relativamente à fronteira final que propusemos para o Pretérito Perfeito. Isso permitiria explicar, por exemplo, a impossibilidade das designadas leituras conjeturais ou hipotéticas com ir + Infinitivo, já que a sobreposição ao momento da enunciação estaria, à partida, bloqueada pelo limite inicial imposto pela própria construção. 


\section{Considerações finais}

Se é certo que existem diferenças significativas que dividem os tempos do passado dos tempos do futuro, é igualmente verdade que podemos encontrar características comuns que os aproximam. Foi nosso objetivo sistematizar e, pela primeira vez, correlacionar algumas dessas especificidades que nos permitiram reagrupar alguns tempos gramaticais do Português.

Um dos pontos em que os tempos do passado e os tempos do futuro divergem consideravelmente prendese com a atribuição do valor de verdade às proposições envolvidas: enquanto o valor de verdade das proposições expressas pelos tempos do passado pode ser aferido, sem problemas, no momento da enunciação, o mesmo não se passa relativamente aos tempos do futuro, tendo em vista que uma situação que ainda não teve lugar não poderá ser considerada, à partida, nem verdadeira nem falsa. Nessa medida, os tempos do futuro são, por natureza, ramificantes, i.e., obrigam à consideração de um conjunto de histórias ou de mundos possíveis, dependente da variabilidade inerente ao curso dos acontecimentos. A atribuição de um valor de verdade às proposições em questão terá, pois, de ter em conta ou um contexto de realização da situação localizado num tempo posterior ao ponto de fala ou uma única história que será selecionada e concebida como marco referencial em detrimento das demais.

No entanto, se nos focarmos mais detidamente em certos tempos gramaticais do Português, verificamos que, apesar das divergências observadas, tempos do passado e tempos do futuro partilham propriedades comuns. Nesse sentido, procurámos, ainda que de forma muito sucinta, pôr em confronto algumas das características do Pretérito Perfeito, do Pretérito Imperfeito, do Futuro Simples e da construção ir + Infinitivo, todos no modo Indicativo.

Observámos que, em certos aspetos, o Pretérito Imperfeito (no domínio do passado) e o Futuro Simples (no domínio do futuro) ostentam comportamentos linguísticos bastante semelhantes, distanciando-se do Pretérito Perfeito e da construção ir + Infinitivo, que, por sua vez, apresentam importantes similaridades entre si.

No que respeita à sua caracterização temporal, assumimos que o Pretérito Imperfeito e o Futuro Simples veiculam informação de âmbito mais geral, uma vez que parecem limitar-se a proceder à mera localização das situações com que se combinam em intervalos anteriores ou posteriores ao momento da enunciação (ou a um outro tempo equiparado), resultando a sua interpretação final da interação entre esse valor temporal de base e as propriedades aspetuais das situações envolvidas, na linha de análises como as de Kamp e Rohrer (1983) ou de Kamp e Reyle (1993); como consequência, observa-se, por exemplo, uma clara assimetria entre o comportamento de eventos e de estados nos referidos contextos. Já a estrutura ir + Infinitivo e o Pretérito Perfeito parecem exigir restrições temporais adicionais, nomeadamente no que se refere à imposição de fronteiras iniciais ou finais às predicações com que coocorrem.

Procurámos, igualmente, estabelecer uma correlação entre as propriedades temporais das formas linguísticas descritas e a maior ou menor apetência pelo surgimento de leituras de natureza modal: quanto mais específica e restritiva é a informação temporal veiculada, menor espaço parece subsistir para o desenvolvimento de outro tipo de interpretações, nomeadamente as que remetem para a modalidade.

\section{Referências}

Anand, Pranav \& Valentine Hacquard (2009) The role of the imperfect in Romance counterfactuals. In. Proceedings of Sinn und Bedeutung 14, pp. 37-50. Disponível online em https://ojs.ub.unikonstanz.de/sub/index.php/sub/article/view/458

Belnap, Nuel \& Mitchell Green (1994) Indeterminism and the thin red line. In J. Tomberlin (ed.), Philosophical Perspectives 8: Logic and Language. Atascadero: Ridgeview, pp. 365-388, 
Besson, Corine \& Anandi Hattiangadi (2014) The open future, bivalence and assertion. Philosophical Studies 167 (2), pp. 251-271.

Besson, Corine \& Anandi Hattiangadi (2020) Assertion and the future. In Sanford Goldberg (ed.) The Oxford Handbook of Assertion. Oxford / Nova York: Oxford University Press, pp. 481-504.

Cipria, Alicia \& Craige Roberts (2000) Spanish imperfecto and pretérito: truth conditions and aktionsart effects in a Situation Semantics. Natural Language Semantics 8 (4), pp. 297-347.

Copley, Bridget (2009) The Semantics of the Future. New York: Routledge Outstanding Dissertations in Linguistics.

Cunha, Celso \& L. Lindley Cintra (1984) Nova Gramática do Português Contemporâneo. Lisboa: Edições Sá da Costa.

Cunha, Luís Filipe (1998) As Construções com Progressivo no Português: uma Abordagem Semântica. Dissertação de Mestrado, Porto: Faculdade de Letras da Universidade do Porto.

Cunha, Luís Filipe (2004/2007) Semântica das Predicações Estativas: para uma Caracterização Aspectual dos Estados. Dissertação de Doutoramento, Faculdade de Letras da Universidade do Porto. Publicação em 2007, Munique: Lincom Europa.

Cunha, Luís Filipe (2019) O Futuro Simples em Português Europeu: entre a temporalidade e a modalidade. Linguística - Revista de Estudos Linguísticos da Universidade do Porto 14 (1), pp. 35-68.

Cunha, Luís Filipe (2021) Propriedades temporais do Futuro Simples em Português Europeu. Estudos de Lingüística Galega 13 (1), pp. 29-66.

Declerck, Renaat (1991) Tense in English: its Structure and Use in Discourse. Londres / Nova York: Routledge.

Declerck, Renaat (2006) The Grammar of the English Tense System. Berlim: Mouton de Gruyter.

Delfitto, Denis \& Pier-Marco Bertinetto (1995) A case study in the interaction of aspect and actionality: the Imperfect in Italian. In. Pier-Marco Bertinetto (ed.) Temporal reference, aspect and actionality, Vol. 1. Torino: Rosenberg \& Sellier, pp. 125-142.

Dendale, Patrick (2001) Le futur conjectural versus devoir épistémique: différences de valeur et restrictions d'emploi. Le Français Moderne 69 (1), pp. 1-20.

Dowty, David (1979) Word meaning and Montague grammar. Dordrecht: Reidel Publishing Company.

Falaus, Anamaria \& Brenda Laca (2014) Les formes de l'incertitude. Le futur de conjecture en espagnol et le présomptif futur en roumain. Revue de linguistique romane 78, pp. 313-366.

Galton, Antony (2006) On the process of coming into existence. The Monist 89 (3), pp. 294-312.

Gennari, Silvia (2000) Semantics and pragmatics of future tenses in Spanish. Hispanic Linguistics at the Turn of the Millennium. pp. 264-281.

Gennari, Silvia (2002) Spanish past and future tenses: Less (semantics) is more. In. From Words to Discourse: Trends in Spanish Semantics and Pragmatics. Elsevier Science, pp. 21-36.

Giannakidou, Anastasia (2014) The futurity of the present and the modality of the future: a commentary on Broekhuis and Verkuyl. Natural Language \& Linguistic Theory 32 (3), pp. 1011-1032. https://doi.org/10.1007/s11049-014-9234-z

Giannakidou, Anastasia \& Alda Mari (2018) A unified analysis of the future as epistemic modality. Natural Language \& Linguistic Theory 36 (1), pp. 85-129. https://doi.org/10.1007/s11049-017-9366-Z

Giomi, Riccardo (2010) Para uma Caracterização Semântica do Futuro Sintético Românico: Descrição e Análise dos Valores do Futuro do Indicativo em Português e em Italiano. Dissertação de Mestrado, Faculdade de Letras da Universidade de Lisboa.

Giorgi, Alessandra \& Fabio Pianesi (1997) Tense and Aspect: from Semantics to Morphosyntax. Oxford / Nova York: Oxford University Press.

Ippolito, Michela (2004) Imperfect modality. In Jacqueline Guéron \& Jacqueline Lecarme (eds.) The syntax of time. Cambridge, MA: MIT Press, pp. 359-387. 
Kamp, Hans \& Christien Rohrer (1983) Tense in texts. In. R. Bauerle, C. Schwarze \& A. von Stechow (eds.) Meaning, Use and Interpretation of Language. Berlim: Walter de Gruyter, pp. 250-269.

Kamp, Hans \& Uwe Reyle (1993) From Discourse to Logic. Introduction to Model-Theoretic Semantics of Natural Language, Formal Logic and Discourse Representation Theory. Dordrecht: Kluwer Academic Publishers.

Laca, Brenda (2016) Variación y Semántica de los Tiempos Verbales: el Caso del Futuro. Documento de trabalho disponível em linha em https://hal.archives-ouvertes.fr/hal-01533046/)

MacFarlane, John (2003) Future contingents and relative truth. The Philosophical Quarterly 53 (212), pp. 321336.

MacFarlane, John (2008) Truth in the garden of forking paths. In Manuel García-Carpintero \& Max Kölbel (eds.) Relative Truth. Oxford: Oxford University Press, pp. 81-102.

Malpass, Alex \& Jacek Wawer (2012) A future for the thin red line. Synthèse 188 (1), pp. 117-142.

Mari, Alda (2009) Disambiguating the Italian future. In Proceedings of Generative Lexicon, pp. 209-216.

Marques, Rui (2020) Epistemic future and epistemic modal verbs in Portuguese. Journal of Portuguese Linguistics 19 (1). DOI: http://doi.org/10.5334/jpl.243

Martin, Robert (1981) Le futur linguistique: temps linéaire ou temps ramifié? (à propos du futur et du conditionnel français). Langages 64, pp. 81-92.

Matos, Sérgio (1996) Aspectos da semântica e pragmática do Imperfeito do Indicativo. Revista da Faculdade de Letras da Universidade do Porto: Línguas e Literaturas, Série II, Vol. 13, pp. 435-474.

Moens, Marc (1987) Tense, Aspect and Temporal Reference. Dissertação de Doutoramento, Universidade de Edimburgo.

Oliveira, Fátima (1986) O Futuro em Português: alguns aspectos temporais e/ou modais. In. Actas do I Encontro Nacional da Associação Portuguesa de Linguística. Lisboa: Associação Portuguesa de Linguística, pp. 353374.

Oliveira, Fátima (1987) Algumas considerações acerca do Pretérito Imperfeito. In. Actas do II Encontro da Associação Portuguesa de Linguística. Lisboa: Associação Portuguesa de Linguística, pp. 78-96.

Oliveira, Fátima (2013) Tempo verbal. In. Eduardo Paiva Raposo et al. (orgs.) Gramática do Português, Vol I, Cap. 15. Lisboa: Fundação Calouste Gulbenkian, pp. 509-553.

Oliveira, Fátima \& Ana Cristina Macário Lopes (1995) Tense and aspect in Portuguese. In. Rolf Thieroff (ed.) Tense systems in European languages, Vol II. Tübingen: Niemeyer, pp. 95-115.

Peres, João Andrade (1993) Towards an integrated view of the expression of time in Portuguese. Cadernos de Semântica 14. Lisboa: Faculdade de Letras da Universidade de Lisboa.

Prior, Arthur (1967) Past, present and future. Oxford: Oxford University Press.

Reichenbach, Hans (1947) Elements of Symbolic Logic. Londres: MacMillan.

Smith, Carlota S. (1991) The Parameter of Aspect. Dordrecht: Kluwer Academic Press.

Stojanovic, Isidora (2014) Talking about the future: Unsettled truth and assertion. In Philippe de Brabanter, Mikhail Kissine \& Saghie Sharifzadeh (eds.) Future Times, Future Tenses. Oxford: Oxford University Press, pp. 26-43.

Vendler, Zeno, (1967) Linguistics in Philosophy. Nova York: Cornell University Press. 